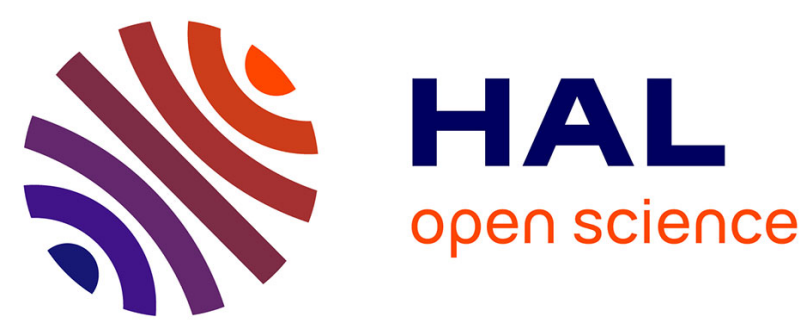

\title{
When nature rebels: international migration, climate change and inequality
}

Luca Marchiori, Ingmar Schumacher

\section{To cite this version:}

Luca Marchiori, Ingmar Schumacher. When nature rebels: international migration, climate change and inequality. 2009. hal-00358759

\section{HAL Id: hal-00358759 \\ https://hal.science/hal-00358759}

Preprint submitted on 4 Feb 2009

HAL is a multi-disciplinary open access archive for the deposit and dissemination of scientific research documents, whether they are published or not. The documents may come from teaching and research institutions in France or abroad, or from public or private research centers.
L'archive ouverte pluridisciplinaire HAL, est destinée au dépôt et à la diffusion de documents scientifiques de niveau recherche, publiés ou non, émanant des établissements d'enseignement et de recherche français ou étrangers, des laboratoires publics ou privés. 


\title{
ECOLE POLYTECHNIQUE
}

WHEN NATURE REBELS: INTERNATIONAL MIGRATION, CLIMATE CHANGE AND INEQUALITY

\author{
Luca MARCHIORI \\ Ingmar SCHUMACHER
}

January 2009

Cahier n 2009-04

\section{DEPARTEMENT D'ECONOMIE}

Route de Saclay

91128 PALAISEAU CEDEX

(33) 169333033

http://www.enseignement.polytechnique.fr/economie/

mailto:chantal.poujouly@polytechnique.edu 


\title{
WHEN NATURE REBELS: INTERNATIONAL MIGRATION, CLIMATE CHANGE AND INEQUALITY
}

Luca Marchiori*

\author{
Ingmar Schumacher ${ }^{\dagger}$
}

January 28, 2009

\begin{abstract}
This article analyzes the link between climate change and international migration. We use a two-country overlapping generations model with endogenous climate change, in which the production in the North generates climate change which negatively affects the productivity of the South. Our main findings are: (i) climate change will increase migration; (ii) small impacts of climate change have significant impacts on the number of migrants; (iv) a laxer immigration policy increases longrun migration, reduces climate change, increases North-South inequality if DRTS are significant; (v) a greener technology reduces long-run migration, provides a doubledividend in favor of the environment, reduces inequality if the migrants' impact to overall climate change is large. The preference over the policies thus depends on whether the policy maker targets inequality, wealth, the number of migrants or the environment, but the qualitative ranking between the policies does not change if the policies are costly.
\end{abstract}

JEL Classification: F 22, J 61, O 13

Keywords: climate change, migration, North-South model, overlapping generations, inequality.

*IRES, Université catholique de Louvain, 3 Place Montesquieu, 1348 Louvain-la-Neuve, Belgium. Email: marchiori@ires.ucl.ac.be.

${ }^{\dagger}$ Department of Economics, Ecole Polytechnique, and Department of Economics, University of Trier. email: ingmar.schumacher@polytechnique.edu, tel.: +33169333038. The author is grateful for financial support from the Chair for Business Economics and the Chair EDF-Sustainable Development at the Ecole Polytechnique. 


\section{Introduction}

Without doubt there is a growing concern over how and whether climate change will affect international migration. Although the economic literature has dealt with many aspects of migration, the treatment of the relationship between climate change and migration has not yet been satisfactory. Our focus in this article is to shed some light on this dark area of economic analysis.

The recently published Stern review on climate change advances an unambiguous message: "An overwhelming body of scientific evidence now clearly indicates that climate change is a serious and urgent issue. The Earth's climate is rapidly changing, mainly as a result of increases in greenhouse gases caused by human activities." (Stern, [39], p.3) This claim is without a doubt now a widely accepted fact in the scientific community. Another commonly anticipated point is that the "poorest countries will be especially hard hit by climate change, with millions potentially pushed deeper into poverty." (Stern [39], p.487) Possible and predicted effects of climate change include land loss due to sea level rise, loss of biodiversity, productivity declines, warmer and drier climates or wetter regions and more extreme weather events (see IPCC [26] ).

As some regions are proner to be affected by several of these adverse effects than others, it seems logical that inhabitants of these regions will try to avoid those effects. However, many poor regions either lack finances to abate or they do not emit enough to have any significant impacts from abatement activity. Usually, mitigation or adaptation are then proposed as the only possible ways of dealing with these problems. As ought to be clear however, those regions that are already extremely poor and vulnerable even before climate change impacts them, will be unable to mitigate or adapt in the usual sense. Therefore, very often the only hope left for people is to move away from the inhabitable area to one which might give them better living conditions.

It is this particular setting which shall be investigated in this article. We shall focus on the link from human activity over climate change to international migration. The main questions which we wish to explore are the following: What are the environmental reasons for people to migrate? What are the welfare effects? What could potentially be welfare-improving? Which are the effects of different policies?

It is well-known that the effects of climate change are difficult to measure. The evident lack of strong data thus requires a more thorough theoretical analysis of a kind which we intend to pursue here. The first section shall give an overview of the data which exist on international migration and climate change. We then build upon a model similar to Galor [19] and investigate, step-by-step, the key issues driving migration in a two- 
country, overlapping generations world with climate change and migration. As climate change is a long-term phenomenon we shall mainly focus on the steady state perspective, but nevertheless allow for the effects of short-run interactions.

Migration between two countries or regions has traditionally been analyzed within the Harris-Todaro model ([22]), see also Ghatak et al. [20] for a survey. The model of Harris and Todaro explains rural-urban migration in a general equilibrium model. However, the static framework of the Harris and Todaro model may miss endogenous feedbacks or can only assume these exogenously. Models which are able to analyze these feedbacks are two country models like Galor [19]. He analyzes the welfare effect migration in a two-country overlapping generations model where he allows for bilateral migration where migration decisions are mainly driven by differences in preferences. Crettez et al. [12] extend Galor's model to include land as a third production factor. ${ }^{1}$ Here we shall focus on climate change as a possible driver behind migration decisions.

Our main findings are as follows: (i) climate change will most likely increase overall migration; (ii) even small impacts of climate change can have significant impacts on the number of migrants; (iii) taking responsibility for its externality a laxer northern immigration policy will increase world migration and worsen climate change; (iv) NorthSouth inequality may increase or decrease via appropriate green or immigration policy; Finally, the type of policy is crucial for the preference over the one or the other, especially if the North tries to pursue several targets simultaneously. The targets we look at are welfare, the policy's implication for climate change on the effect on North-South inequality.

\section{Climate change and migration: facts and future}

This section is designated to provide an overview of important facts on climate change and migration, as well as to present reasons for the particular assumptions which we use later throughout the article. In the first part we summarize key facts on climate change and in the second part we focus on the environment as a leading cause of migration.

\footnotetext{
${ }^{1}$ The literature has also focused on the impact of migration on the economy of the destination and origin countries. Migration can affect labor market outcomes such as wages (Borjas [28]) or unemployment (Bencivenga [6]), pension systems (Razin and Sadka [37]) or human capital formation (Vidal [41]) and growth (Beine et al. 2001).
} 


\subsection{Climate change}

The IPCC Third Assessment Report (TAR) concludes that the emission of greenhouse gases from human production activity led to an increase in $\mathrm{CO}_{2}$ equivalent concentrations from $290 \mathrm{ppm}$ to $440 \mathrm{ppm}$ during the course of the past 150 years. The more greenhouse gases accumulate in the atmosphere the more they will prevent the infrared radiation emitted by the sun to escape the atmosphere of the Earth. This then leads to a warming which is expected to lie anywhere between $2{ }^{\circ} \mathrm{C}$ and $6{ }^{\circ} \mathrm{C}$ for the next 100 years, depending on the path we humans choose for economic development (see IPCC TAR [27]). Most of these increases in greenhouse gases must be attributed to the rich countries. For example, the estimates provided by Enerdata in its Energy Statistics Yearbook suggest that the European Union, North America and Japan together account for close to $60 \%$ of annual world emissions, even though they host only $16 \%$ of the world population.

The main reason for this disparity is the use of the amount of primary energy resources ${ }^{2}$ in production, which accounts for most of the $\mathrm{CO}_{2}$ emitted into the atmosphere. The use of these inputs differs drastically between the developed world and the less developed world. Estimates from the International Energy Annual 2004 suggest that Northern America, Europe, Japan and China together account for roughly $65 \%$ of the total world primary energy use. In comparison to this, the Least Developed Countries use roughly $5 \%$ of total world primary energy (IEA [2]).

The costs of climate change can vary drastically, depending on the size of the change in temperature. Whereas the IPPC in various publications suggests that an increase of $2^{\circ} \mathrm{C}$ from pre-industrial levels may lead to economic costs in the range of $2 \%$ to $5 \%$ of GWP per year, increases above that level may lead to potentially catastrophic costs.

In addition, the distribution of the damages is extremely particular to regions. It is expected that the less developed countries will have to face close to $80 \%$ of the world damages from climate change. This is particularly troublesome for several reasons. Most of the developing countries already face the problem of binding income constraints. It is estimated that in 2004 around 800 million people were at risk of hunger (FAO) and malnutrition accounts for approximately four million deaths annually. It is believed that half of those deaths from malnutrition arise in Africa alone. The current estimates suggest that a temperature increase of $2-3^{\circ} \mathrm{C}$ will potentially raise the number of people at risk of hunger by $30-200$ million. If the temperature increases by more than $3{ }^{\circ} \mathrm{C}$, which is a likely scenario of the IPCC, then the number of people facing hunger could increase by an

\footnotetext{
${ }^{2}$ According to IEA, in 2004 approx. $80 \%$ of world total primary energy supply came from oil, coal and gas.
} 
additional 250-500 million. It is also believed that most of these will be observed in Africa and Western Asia (Warren et al. [36]). The World Health Organization even estimates that an additional one to three million people will then die from malnutrition ${ }^{3}$, diarrhea or malaria.

Another problem of the effects of climate change concerns the productive capacity of countries. For example, the value added to GDP from agriculture is around $33 \%$ for less developed countries, whereas for upper middle income countries only $6.2 \%$ (WDID [4]). In addition, around $54 \%$ of the developing world's population works in the agricultural sector but only $7 \%$ of the developed countries' population. These numbers can be up to $90 \%$ high for some of the Sub-Saharan Countries (FAO [18]). The temperature in those countries increased on average by $3^{\circ} \mathrm{C}$ during the past decade whereas the total amount of rainfall decreased by roughly 4\% between 1960 and 2000. Some countries even face decreases up to $20 \%$ like Burundi or Rwanda. This suggests that overall these countries have become drier. If they however face binding income constraints, have a high share of agriculture in GDP and in addition if most of the population is rural and works in the agricultural sectors, then these countries will face more severe consequences from climate change than can initially be grasped.

Remark 1 Two preliminary conclusions can be drawn from the analysis above:

(1) Developed countries are the main emitters and therefore the predominant source of human induced climate change,

(2) Developing countries are likely to face the strongest impact of climate change.

\subsection{Migration}

Here we wish to give a list of examples where migration occurred due to environmental factors. We shall then proceed to investigate what several researchers suggest will be the future of migration from climate change in particular.

Examples are, contrary to what some critics might suggest ${ }^{4}$, in fact abundant. A quick reading of the existing literature provides many cases. For example, droughts in the US displaced more than 30,000 people in the 1930s (Rosenzweig and Hillel [38]); a tsunami in Indonesia in 2004 displaced 500,000 people (FIG [34]); droughts in Burkina Faso or

\footnotetext{
${ }^{3}$ For example, Swart et al. [40] estimate that temperate cereals might be faced by yield decreases of up to $22 \%$, thereby substantially increasing food shortages.

${ }^{4}$ For a critical opinion see Black [7].
} 
Sudan from 1968-1973 displaced around 1,000,000 people (Afolayan and Adelekan [1], Hugo [24]). ${ }^{5}$

Several of these cases deserve an additional remark. In Sudan it seems that only a part of the household migrates (the male usually) and then returns after the drought stops. Similar observations hold for Ethiopia where the young generations seem of migration when droughts occur (Afolayan and Adelekan [1]). This suggests two possibilities: either the costs to migrate are too high for everyone to bear such that only a part of the household is able to leave; or people are particularly attached to their homes and expect better times to come again. However, these droughts usually last a short period of time and are therefore only transitory. One would expect that areas where irreversible changes in the climate lead to a permanently higher level of aridity would not see return migration. This is supported two-folded by Henry et al. [23]. Firstly, for the case of Burkina Faso they show that people from arid regions are more likely to migrate (temporarily and permanently) than those from wetter regions. Secondly they suggest that long-run "migrations are likely to be more influenced by a slow-acting process such as land degradation than by episodic events such as droughts." A similar conclusion is drawn by Chen et al. [31], who suggest the population distribution in China depends mainly on the proportion of arable land. Therefore, if that proportion changes due to environmental deterioration one must also expect a change in the population distribution.

Apart from droughts one can observe that extreme weather events also lead to permanent migration. For example, according to Morris et al. [32], after a strong hurricane in Honduras and Nicaragua in 1998 the amount of migrants to the US and adjacent countries rose sharply. Clearly, economic deprivation thus induces people to migrate, but it can also simply be in order to avoid the same event happening in the future. For example, even one year after the Hurricane Katrina had passed, Louisiana had a $4.87 \%$ lower population due to emigration (Les [10]).

In Indonesia a tsunami in 2004 displaced around 500,000 people (International Federation of Surveyors (FIG) [34]) internally, meaning they did not leave the country. However, one can expect that they increased the economic and social pressures in the areas they moved into and will therefore effect the migration decisions in those places. Thus, people who were before on the brink of migrating might now finally decide to move.

Remark 2 From this quick overview we can draw a particular conclusion: Permanent migration seems to occur because of irreversible or long-lasting problems like desertification or continuous environmental degradation which removes the subsistence possibility

\footnotetext{
${ }^{5}$ For more examples, see e.g. McLeman [30], Ezra [15], Morries et al. [32], Kaye [29].
} 
of people; or simply because people expect further extreme events in the future and try to avoid these.

These results therefore point toward a further analysis of the effects which climate change has on the expected future migration decisions.

\section{The future of migration?}

It is estimated that the amount of people affected by natural disasters has tripled to a staggering number of 2 billion people over the course of one decade only. Approximately 211 million people are believed to be affected each year. Scientific evidence suggests that this amount is likely to increase the larger the change in temperature from climate change, as this leads to more floods, extreme weather events and desertification (IPCC, Stern review).

Also, as approximately two billion people are living in arid, semi-arid and sub-humid regions, one can expect that only small climatic changes will induce particularly large damages there. For example, it is suggested that the resilience of many arid regions is already weakened. Estimates conclude that up to 20 percent of drylands are degraded, droughts seem to become more frequent (Millennium Ecosystem Assessment (MA) [3]), groundwater depletion intensifies and groundwater quality deteriorates due to increased fertilizer use ( Brown [8] and Brown et al [9]). It is thus clear that if the temperature and the weather variability increase as is expected, then the resilience of the ecosystems will have difficulties to support further stresses.

Many people will then only have the option to leave their homes in order to find a place which is able to support them. For example, the number of migrants increases annually by approximately three million people, half of which come from Africa. It is believed that most of these come from rural areas with severe land degradation. Estimates suggest that more than 135 million people could be at risk of needing to migrate due to desertification alone (INCCCD [25]), and roughly 200 million due to sea-level rise (Myers [33]). If desertification and land degradation thus continues as expected, then the number of migrants will shoot up, too.

Another reason for migration can be the effect of climate change on health and thus working ability. Flavin and Tunali [17] inform that illnesses like cholera, malaria and others are very likely to spread vastly due to increased temperatures and higher humidity. They inform that an increase of around $3^{\circ} \mathrm{C}$ can potentially increase mosquito-transmitted diseases by up to two times in tropical regions and by up to 10 times in areas like Europe. Higher water temperatures can increase the production of algae, which again can increase the probability of cholera outbreaks. It is estimated that around 3 million people die from 
malaria each year with up to 500 million suffering near fatal consequences. Additionally, around 17.3 million deaths worldwide (around $33 \%$ of total) are believed to be caused by infectious diseases. These deaths are thought to be caused due to shortages of water which result in more use of contaminated water and lower cleanliness (see World Health Report (1996) [35]). The dark figures for lost working hours due to illness from infectious diseases should by far exceed the deaths. If we use the same ratio as near fatal consequences to fatalities for malaria (ratio of 170 ), this leads to a (certainly too large) figure of 3 billion people losing some working hours. This however can provide some estimate for lost working hours or reduction in productivity. If this extrapolation is only marginally correct, then this presumes a strong effect of climate change on productivity.

Faced with these figures one cannot easily reject the need to further investigate the impact of climate change on migration and its feedbacks. We shall therefore develop a theoretical model which incorporates these feedbacks. Through this we expect to add to the understanding of the relationship between the economy, migration and climate change.

\section{The Model}

Here we construct a two-country, general equilibrium, overlapping generations model. As we wish to concentrate on analyzing international migration we shall simply assume that firms are profit maximizers in a perfectly competitive world with international capital mobility. Generations however first analyze how much welfare they are likely to obtain at home and then compare this to the welfare they might get from migrating to another region. In case migration is expected to leave them better of, then they shall migrate. Our approach is designed to understand, step-by-step, the welfare implications from migration when climate change plays a significant role for welfare. Most of the article will concern itself with the steady-state perspective of our dynamic model. In terms of notation we shall denote with small letters per capita, with large letters total population. The first subscript refers to the country, the second to the point in time. We write subscript $i$ to denote a solution which applies to both north and south, such that $i=N, S$. Constant returns to scale will be abbreviated by CRTS, decreasing returns to scale by DRTS and total factor productivity by TFP. 


\subsection{The firm's problem}

We assume that in each region there exists a representative firm which produces in a perfectly competitive market using capital and labor as inputs. The production function in each country is of a Cobb-Douglas type where we allow for decreasing returns to scale, such that $Y_{i t}=A_{i t} K_{i t}^{\alpha} L_{i t}^{\beta}$, and $\alpha+\beta \leq 1$.

The discussion on whether production is subject to DRTS or CRTS has been ongoing for quite some while. We allow for both in order to have results which are as broad as possible. DRTS have also been used in theoretical models by e.g. Facchini and Willmann [16] and are empirically supported by the estimations of the Global Trade Analysis Project (GTAP) as well as by other empirical studies (e.g. Basu and Fernald [5]). On the one hand, DRTS makes one vulnerable to the replication argument, which is solely a theoretical argument suggesting that a firm producing under DRTS can split in two and thereby increase overall output. On the other hand, DRTS seems to be a realistic assumption given the empirical results that we have. What we do here is give up a slight amount of theoretical rigor in favor of what is the apparently more realistic assumption. A partial reconciliation between the use of DRTS and the replication argument is that allowing for DRTS can also imply that one views other unpriced and roughly constant factors (like land or other externalities) as important other contributors to production. We would then have for example land, $L$, such that $Y_{i t}=B_{i t} K_{i t}^{\alpha} L_{i t}^{\beta} L_{i}^{1-\alpha-\beta}$, and via simplification arrive at $Y_{i t}=A_{i t} K_{i t}^{\alpha} L_{i t}^{\beta}$ with $A_{i t}=B_{i t} L_{i}^{1-\alpha-\beta}$ (see also Cigno [11] for a model with a three factor CRTS production function and endogenous population).

TFP in the North is constant, $A_{N t}=A_{N}$, whereas the one in the south is $A_{S t}=A_{S}\left(T_{t}\right)$, where $T_{t}$ is the change in temperature at time $t$ from human induced climate change. We view this as a proxy for the effect that climate change bears on production. The assumption of climate change affecting TFP can be rationalized by taking TFP as accounting for any residual factor of production which is unpriced. Firstly, assume TFP accounts for the amount of land used in production, then increases in the sea-level or desertification reduce the amount and productivity of land. Secondly, assume TFP captures health effects, then one can argue that climate change is expected to increase the amount of malaria which has significant impacts on the health and thus productivity of workers. Finally, the assumption that climate change only impacts the south derives from the observations presented in the previous section. We assume $A_{S} \geq A_{S}(T), \forall T>\underline{T}$, where $\underline{T}$ denotes the level of temperate without human induced climate change. This assumption allows us to compare the different scenarios with and without climate change.

Firms then maximize profits according to $\max _{\left\{L_{i t}\right\}} \Pi_{i t}=A_{i t} K_{i t}^{\alpha} L_{i t}^{\beta}-w_{i t} L_{i t}$, for $i=N, S$, 
where equilibrium wages are given by

$$
w_{i t}=\beta A_{i t} K_{i t}^{\alpha} L_{i t}^{\beta-1} .
$$

Following Hahn and Solow [21] we assume that in the case of DRTS the excess profits are distributed to the investors, which is the young generation of the previous period, such that $\Pi_{i t}=(1-\beta) A_{i t} K_{i t}^{\alpha} L_{i t}^{\beta}$, which gives a return to a unit of capital of

$$
R_{i t+1}=(1-\beta) A_{i t+1} K_{i t+1}^{\alpha-1} L_{i t+1}^{\beta} .
$$

In the case of CRTS, we of course have $1-\beta=\alpha$ and there are no excess profits.

\subsection{The generation's problem}

The generations in each country choose according to a two-step procedure. In the first step they calculate their maximum utility at home. In the second step they calculate whether it is more profitable for them to migrate or to stay in their home country.

In the first step we thus have

$$
\begin{aligned}
& \max _{s_{i t}} u\left(c_{i t}, d_{i t+1}\right) \quad \text { subject to } \\
& w_{i t}=s_{i t}+c_{i t}, \\
& R_{i t+1} s_{i t}=d_{i t+1} \text {, }
\end{aligned}
$$

for $i=N, S$, where $w_{i t}$ refers to wages in region $i$ at time $t, u\left(c_{i t}, d_{i t+1}\right)$ is the utility of consuming $c_{i t}$ when young and $d_{i t+1}$ when old, $s_{i t}$ are the savings and $R_{i t+1}$ the return on the savings. We shall use log-utility for simplicity, where $u\left(c_{i t}, d_{i t+1}\right)=\log \left(c_{i t}\right)+$ $\rho \log \left(d_{i t+1}\right)$. This gives $s_{i t}=\rho w_{i t} /(1+\rho)$. Consumption will thus be $c_{i t}=w_{i t} /(1+\rho)$ and $d_{i t+1}=\rho w_{i t} R_{i t+1} /(1+\rho)$. We write indirect utility in the steady state as

$$
\tilde{u}_{i}=\log \left(\frac{w_{i}}{1+\rho}\right)+\rho \log \left(\frac{\rho R w_{i}}{1+\rho}\right) .
$$

Then, in the second step the agent compares whether his lifetime utility will be higher when migrating, such that

$$
\begin{aligned}
\Delta_{i} & =\tilde{u}_{j}-\tilde{u}_{i}, & \text { if } & \tilde{u}_{j}>\tilde{u}_{i} \\
& =0 & \text { if } & \tilde{u}_{j} \leq \tilde{u}_{i} .
\end{aligned}
$$


If this difference is positive, then a proportion of the generation will migrate to the other region. Furthermore, if an agent wants to migrate, this will cost him an amount $c_{i} x$ and $d_{i} x$, where $x \in(0,1)$ reflects adaptation costs in various forms. Indeed, we wish to keep these migration costs as general as possible, allowing for both subjective and financial costs. Our preferred interpretation would be subjective costs though, which are reflected in the ex ante probability of finding a job or in the welfare loss (expressed in consumption units) of having to adopt to different cultures and circumstances. In this sense, we avoid putting an explicit structure behind the level of migration costs. What definitely also affects migratory costs are the government policies directed towards migration. Whereas some countries are rather liberal on the amount of migrants that they take, other countries restrict the inflow of migrants and regions like the EU even build migratory camps in Africa to catch potential migrants even before they can attempt to cross the boarder.

$>$ From this we obtain that an agent born in the South is in equilibrium indifferent between living in the South and migrating to the North if

$$
\log \left(x \frac{w_{j}}{w_{i}}\right) \leq-\frac{\rho}{1+\rho} \log \left(\frac{R_{j}}{R_{i}}\right) .
$$

The population accumulates according to $L_{j t+1}=L_{j t}+m_{i t+1} L_{i t}$ and $L_{i t+1}=L_{i t}-m_{i t+1} L_{i t}$, where $m_{i t} \geq 0$ refers to the percent of people migrating in that point of time. We denote the total population which has migrated as $\sum_{s=1}^{t} m_{s} L_{s-1}=M_{t}$. In the steady state we then have $L_{N}=\bar{L}_{N}+M$ and $L_{S}=\bar{L}_{S}-M$, where $M \gtrless 0$.

\subsection{International capital market}

In the framework presented here we can solve for both the case of no trade in capital and for the case of free trade. We assume that capital depreciates fully during the course of one generation. This assumption for example finds support in de la Croix and Michel [13]. No international capital mobility implies that savings $s_{i t}$ in one region become the capital $k_{i t}=K_{i t} / L_{i t}$ of that region in the next period, $s_{i t}=k_{i t+1}$. Free trade in capital requires that total world capital stock is equal to total world savings, such that $L_{N t+1} k_{N t+1}+L_{S t+1} k_{S t+1}=L_{N t} s_{N t}+L_{S t} s_{S t}$, and perfect competition on the international capital market implies $R_{N}=R_{S}, \forall t$.

Henceforth we shall denote frictionless international capital markets as integrated and the case of no international capital mobility shall be called autarky. We already start with a first important result which we provide in the subsequent proposition. 
Proposition 1 Given the optimization problem of the firm and the problem of the generations, the long-run results of the integrated case are equivalent to those of the autarky case.

Proof 1 In the autarky case the interest rate is given by $R_{i}=\frac{(1-\beta)(1+\rho)}{\beta \rho}$. As both $\beta$ and $\rho$ are the same for north and south this implies that both interests rates are the same. As $R_{N}=R_{S}$ by assumption in the integrated case, we can solve for $K_{S}=$ $\left[\frac{A_{N}}{A_{S}}\left(\frac{L_{N}}{L_{S}}\right)^{\beta}\right]^{\frac{1}{\alpha-1}} K_{N}$, which together with the clearing of the world capital market implies that the long-run capital stock is the same in both the integrated and autarky cases.

This proposition therefore allows us to derive the results without having to subsequently compare both the integrated and the autarky case. ${ }^{6}$

\subsection{The climate sector}

The climate sector is as follows: The total stock of North's capital drives the amount of emissions of $\mathrm{CO}_{2}$ equivalent gases, denoted $E_{t} \cdot \mathrm{CO}_{2}$ equivalent concentrations $Z_{t}$ are increased by emissions and reduced by a natural decay. The resulting temperature is non-linearly increased by $\mathrm{CO}_{2}$ equivalent concentrations.

$$
\begin{aligned}
E_{t} & =\mu K_{N t} \\
Z_{t} & =(1-\delta) Z_{t-1}+\gamma E_{t}, \\
\Delta T_{t} & =g\left(Z_{t}\right),
\end{aligned}
$$

with $g^{\prime}(Z)>0$ and $g^{\prime \prime}(Z)<0$ and initial condition $T_{0}=\underline{T}$. Then, the temperature change from human production activities affects the productivity in the south, such that $A_{S t}=A_{S}\left(T_{t}\right)$. Our interpretation of the temperature change is that it measures the deviation from the pre-industrial climate level caused by productive activity.

As observed in the previous section, we assume that emissions from the south are negligible. This assumption is even strengthened if we were to consider the South as being composed of small developing countries only. We know that large emerging economies like China or India represent $18.4 \%$ and $4.9 \%$ of the world's $\mathrm{CO}_{2}$ emissions in 2004, while

\footnotetext{
${ }^{6}$ It should be clear that this result only holds if preference and production parameters are the same and in the absence of any taxation or subsidy.
} 
Western Europe, United States, Canada and Japan contribute together $46 \%$ of total emissions. African countries and other developing countries like Bangladesh or small Pacific Islands represent negligible amounts of the world's $\mathrm{CO}_{2}$ emissions.

\section{Solving the model}

To summarize, we have the following equations at steady state:

$$
\begin{aligned}
w_{i} & =\beta A_{i} K_{i}^{\alpha} L_{i}^{\beta-1}, \text { where } A_{S}=A_{S}\left(K_{N}\right) \\
R_{i} & =(1-\beta) A_{i} K_{i}^{\alpha-1} L_{i}^{\beta}, \\
K_{S} & =\left[\frac{A_{N}}{A_{S}}\left(\frac{L_{N}}{L_{S}}\right)^{\beta}\right]^{\frac{1}{\alpha-1}} K_{N}, \\
K_{N}+K_{S} & =L_{N} s_{N}+L_{S} s_{S}, \\
s_{i} & =\frac{\rho w_{i}}{1+\rho} \\
\log \left(x \frac{w_{j}}{w_{i}}\right) & =-\frac{\rho}{1+\rho} \log \left(\frac{R_{j}}{R_{i}}\right), \\
\Delta T & =g\left(\frac{\gamma \mu}{\delta} K_{N}\right) . \\
L_{N}+L_{S} & =\bar{L}_{N}+\bar{L}_{S} .
\end{aligned}
$$

To remind, we have $A_{S}=A_{S}(T)$ with $A_{S}^{\prime}(T)<0$. At steady state we know that temperature is a function of the capital stock in the North and with some abuse of notation we shall denote $A_{S}(T)$ simply as $A_{S}\left(K_{N}\right)$. Equation (9) gives wages in each country, (10) the interest obtained on investing a unit of capital, (11) is equality of interest rates on the international market, (12) is the market clearing condition for capital due to international capital mobility, (13) gives optimal savings in each country, (14) holds if no one from country $i$ wants to migrate to country $j$, and (15) is the steady state temperature, a proxy for climate change. For the moment we shall not introduce any policy considerations yet.

The following assumption is based on empirical evidence and helps us to focus our analysis.

Assumption 1 Throughout the article we assume that $A_{N 0}>A_{S 0}$, meaning that TFP in the north is higher at $t=0$ than in the south. Furthermore, in accordance with the data, we have $\bar{L}_{N}<\bar{L}_{S}$. 
Though the model implicitly allows for two-way migration, the conditions given in Assumption 1, which are easily verified through data, will imply that in the long-run only one way migration will occur.

Proposition 2 summarizes the results in section 4.

Proposition 2 Given the problem as described in equations (9) to (16) we find that endogenous climate change is a significant propagator of world migration and reduces per capita welfare in both the North and the South.

Due to the various feedbacks involved we shall derive these results step-by-step, where we firstly allow for no feedbacks and then switch them on one after the other.

\subsection{Benchmark case}

Firstly we assume no climate change effect on total factor productivity and no labor mobility but international capital mobility. The steady state capital stock will then be given by $K_{i}=\left[\frac{\rho}{1+\rho} \beta A_{i} L_{i}^{\beta}\right]^{\frac{1}{1-\alpha}}$. This leads to $w_{i}=\left[\beta A_{i}\left(\frac{\rho}{1+\rho}\right)^{\alpha} L^{\alpha+\beta-1}\right]^{\frac{1}{1-\alpha}}$ and $R_{i}=$ $\frac{(1-\beta)(1+\rho)}{\beta \rho}$. We denote indirect utility in the benchmark case by $\tilde{u}^{a}$ and it will be given by

$$
\tilde{u}_{i}^{a}=\Phi+\frac{1+\rho}{1-\alpha} \log \left(\beta A_{i} L_{i}^{\alpha+\beta-1}\right)
$$

where $\Phi=\frac{\alpha(1+\rho)}{1-\alpha} \log \left(\frac{\rho}{1+\rho}\right)+\log \left(\frac{1}{1+\rho}\right)+\rho \log \left(\frac{1-\beta}{\beta}\right)$. Given the utility and production functions are the same, then in the case of CRTS the only difference between indirect utility of the two countries comes from the TFP. By Assumption 1 we thus know that $\tilde{u}_{N}^{a}>\tilde{u}_{S}^{a}$. Under DRTS a larger $L_{i}$ implies a smaller $\tilde{u}_{i}^{a}$.

In this benchmark case we obtain a temperature of

$$
T^{a}=g\left(\frac{\gamma \mu}{\delta}\left[\frac{\rho}{1+\rho} \beta A_{N} L_{N}^{\beta}\right]^{\frac{1}{1-\alpha}}\right) .
$$

The steady state change in temperature is therefore solely driven by the productive capacity of the North. 


\subsection{Benchmark and migration}

We now move to the case of benchmark with migration. The equilibrium condition for migration from the south to the north then implies $x w_{N}=w_{S}$. Rewritten, we obtain the condition that no one moves from the South to the North if

$$
x^{1-\alpha} A_{N} L_{N}^{\alpha+\beta-1}=A_{S} L_{S}^{\alpha+\beta-1} .
$$

A steady state in migration from the south to the north then exists ${ }^{7}$, where we denote the steady state level of $M$ as $M^{a m}$, if $x^{1-\alpha} A_{N} \bar{L}_{N}^{\alpha+\beta-1}>A_{S} \bar{L}_{S}^{\alpha+\beta-1}$. We can solve for the total amount of migrants in the steady $\operatorname{state}^{8}$, given by

$$
M^{a m}=\frac{\left(A_{S}\right)^{\frac{1}{\alpha+\beta-1}} \bar{L}_{S}-\left(x^{1-\alpha} A_{N}\right)^{\frac{1}{\alpha+\beta-1}} \bar{L}_{N}}{\left(A_{S}\right)^{\frac{1}{\alpha+\beta-1}}+\left(x^{1-\alpha} A_{N}\right)^{\frac{1}{\alpha+\beta-1}}} .
$$

We denote indirect utility in this case by $\tilde{u}_{i}^{a m}$ and it will be given by

$$
\begin{aligned}
& \tilde{u}_{S}^{a m}=\Phi+\frac{1+\rho}{1-\alpha} \log \left(\beta A_{S}\left(\bar{L}_{S}-M^{a m}\right)^{\alpha+\beta-1}\right), \\
& \tilde{u}_{N}^{a m}=\Phi+\frac{1+\rho}{1-\alpha} \log \left(\beta A_{N}\left(\bar{L}_{N}+M^{a m}\right)^{\alpha+\beta-1}\right)
\end{aligned}
$$

Thus we obtain that if one allows for migration, then $\tilde{u}_{S}^{a m}>\tilde{u}_{S}^{a}$, whereas $\tilde{u}_{N}^{a m}<\tilde{u}_{N}^{a}$. Therefore, the south benefits from international migration whereas the north loses. Under CRTS there is no effect on steady state welfare from migration.

Steady state temperature is then

$$
T^{a m}=g\left(\frac{\gamma \mu}{\delta}\left[\frac{\rho}{1+\rho} \beta A_{N}\left(\bar{L}_{N}+M^{a m}\right)^{\beta}\right]^{\frac{1}{1-\alpha}}\right) .
$$

Since there are now more people living in the North which all pollute according to the northern living standards, this will unambiguously lead to an increase in emissions and therefore long-run temperature.

${ }^{7}$ Proof: We check whether the equilibrium condition can exist by varying $M$ along its domain $\left[0, \bar{L}_{S}\right]$. We get $\lim _{M \rightarrow 0} x^{1-\alpha} A_{N} L_{N}^{\alpha+\beta-1}>\lim _{M \rightarrow 0} A_{S} L_{S}^{\alpha+\beta-1}>0$, and $\lim _{M \rightarrow \bar{L}_{S}} x^{1-\alpha} A_{N} L_{N}^{\alpha+\beta-1}<$ $\lim _{M \rightarrow \bar{L}_{S}} A_{S} L_{S}^{\alpha+\beta-1}$. Since $x^{1-\alpha} A_{N} L_{N}^{\alpha+\beta-1}$ is a monotonically decreasing function of $M$ and since $A_{S} L_{S}^{\alpha+\beta-1}$ is a monotonically increasing function of $M$ from a positive number to infinity we conclude that a unique steady state exists if $x^{1-\alpha} A_{N} \bar{L}_{N}^{\alpha+\beta-1}>A_{S} \bar{L}_{S}^{\alpha+\beta-1}$.

${ }^{8}$ Under CRTS a steady state can only exist in the knife-edge case of $x^{1-\alpha} A_{N}=A_{S}$. 


\subsection{Benchmark with climate}

Here we shall assume that there is a climate change effect on total factor productivity in the South but no migration possibilities. We denote indirect utility by $\tilde{u}_{i}^{a c}$. In this case the North will grow to the same long-run level of capital as in the benchmark case and end up with the same indirect utility, such that $\tilde{u}_{N}^{a c}=\tilde{u}_{N}^{a}$.

The steady state capital stock of the south is however depending on the amount of climate change induced by the production of the north. The productivity in the south can then be written $A_{S}=A_{S}\left(\left[\frac{\rho}{1+\rho} \beta A_{N} L_{N}^{\beta}\right]^{\frac{1}{1-\alpha}}\right)$. Therefore, the indirect utility of the south at steady state will be given by

$$
\tilde{u}_{S}^{a c}=\Phi+\frac{1+\rho}{1-\alpha} \log \left(\beta A_{S}\left(K_{N}\right) L_{S}^{\alpha+\beta-1}\right)
$$

which implies that $\tilde{u}_{S}^{a c}<\tilde{u}_{S}^{a}<\tilde{u}_{N}^{a c}=\tilde{u}_{N}^{a}$. As expected, the externality imposed by the north on the productive capacity of the south reduces total welfare in the south.

Since there are no migrants in this scenario and since the integrated case is equivalent to the autarky case, we observe no change in production in the north, and therefore no divergence from the total emissions in the benchmark case.

\subsection{Benchmark with climate and migration}

We now extend the previous case by allowing for migration. A steady state in migration from the south to the north then exists ${ }^{9}$, where we denote the steady state level of $M$ as $M^{a c m}$, given that $x^{1-\alpha} A_{N} \bar{L}_{N}^{\alpha+\beta-1}>A_{S}\left(K_{N}\right) \bar{L}_{S}^{\alpha+\beta-1}$. The total amount of migrants in the steady state is then given by

$$
M^{a c m}=\frac{\left(A_{S}\left(K_{N}\right)\right)^{\frac{1}{\alpha+\beta-1}} \bar{L}_{S}-\left(x^{1-\alpha} A_{N}\right)^{\frac{1}{\alpha+\beta-1}} \bar{L}_{N}}{\left(A_{S}\left(K_{N}\right)\right)^{\frac{1}{\alpha+\beta-1}}+\left(x^{1-\alpha} A_{N}\right)^{\frac{1}{\alpha+\beta-1}}} .
$$

We know that $\frac{\partial K_{N}}{\partial M}>0$. This implies more climate change and therefore TFP in the south with migration is lower than if one does not allow for migration. In terms of indirect utility we can then conclude that $\tilde{u}_{S}^{a c m}<\tilde{u}_{S}^{a m}$ iff $M^{a c m} \geq M^{a m}$. The denominator of equation (23) is increasing when $\Delta A_{S}<0$ and the nominator is increasing when $\Delta A_{S}<0$. This comes about because migration implies two things: Firstly,more migration means more climate

\footnotetext{
${ }^{9}$ Proof: $\lim _{M \rightarrow 0} L H S>\lim _{M \rightarrow 0} R H S>0$, and $\lim _{M \rightarrow \bar{L}_{S}} L H S<\lim _{M \rightarrow \bar{L}_{S}} R H S$.
} 
change which reduces income in the south; secondly, more migration implies higher per capita steady state income in the south. It is this cumulative effect where more migration implies further climate change which leads to $M^{a c m}>M^{a m}$. We can therefore conclude that $\tilde{u}_{S}^{a c m}<\tilde{u}_{S}^{a m}$.

The strength of climate change will be given by

$$
T^{a c m}=g\left(\frac{\gamma \mu}{\delta}\left[\frac{\rho}{1+\rho} \beta A_{N}\left(\bar{L}_{N}+M^{a c m}\right)^{\beta}\right]^{\frac{1}{1-\alpha}}\right) .
$$

Therefore, $T^{a c m}>T^{a m}$. In this scenario therefore, not only the direct migration incentives play a vital role, but also the cumulative effects of more migrants. If more migrants also increase emissions in the north and therefore further reduce income in the south, this can imply a strengthening of the migration incentive and will increase climate change further.

\subsection{A Data Experiment}

Our objective is to give some numbers to these otherwise analytical results. This is supposed to be viewed as a rough exercise which allows us to extrapolate some numerical implications of the model. We take data from today, extrapolate into the future (year 2050 ), and then use these estimates as an approximation for the steady state values.

GTAP data suggests that World GDP in the year 2000 is 31.278 billion US $\$$, of which the US, Western Europe and Japan have $70 \%$. We assume those will be the migrants destination countries (North). The South is then composed of most of the remaining countries of the world ${ }^{10}$. Assuming a growth rate of $1 \%$ for the North and $2 \%$ for the South, we calculate World GDP in 2050 to be 36 bn for the North and 25 bn for the South. Total world population is 6.6 billion, of which US, Western Europe, Japan currently hold 17\%. In the year 2050, the estimates of the World Population Prospects are 1.1bn for Europe plus Northern America, and 8bn for the rest of the world. In the year 2000, 52.5 million migrants born in the South live in the North (UN data and [14]). We take this as the baseline case with migration but without climate change. The average sources of GDP worldwide are: skilled plus unskilled labor, giving $\beta=0.44$, and capital, giving $\alpha=0.37$, which suggests significant decreasing returns.

Knowing $Y, \alpha, L, \beta$, we can use our Cobb-Douglas functional form $Y=A K^{\alpha} L^{\beta}$ to calculate $K_{i}$ as follows: take the interest rate $r_{i}=\alpha A_{i} K_{i}^{\alpha-1} L^{\beta}$, then divide by $Y$, gives $r / Y=\alpha / K$. Solve for $K$, gives $K=\alpha Y / r$. We know $\alpha$ and $Y$, assume $r=1.02$, then

\footnotetext{
${ }^{10}$ We do not consider Australia and New-Zealand in our calculations.
} 
we can calculate $K_{N}$ and $K_{S}$. We then calculate $A_{i}$ from solving the income equation for $A$, giving $A=Y /\left(K^{\alpha} L^{\beta}\right)$. Independent of the scaling, the ratio $\sigma \equiv A_{S} / A_{N}$ is always the same. Rewriting equation $(23)$ as $x=\sigma^{1 /(1-\alpha)}\left(L_{N} / L_{S}\right)^{(1-\alpha-\beta) /(1-\alpha)}$, we obtain the $x$ that matches the value of migrants in 2000, namely $x=0.27$.

Having now constructed the variables that we need, we proceed to calculate the effects of climate change on steady state migration. Since there exists barely any data or knowledge of the consequences of climate change on the productive capacity, we take a shortcut and assume that climate change visualizes as a percentage decline in $\sigma$. Table 3 shows that the proportion of migrants in the North, $M /\left(\bar{L}_{N}+M\right)$, will change from $9 \%$ to up to $35 \%$ if the ratio of productivity $\sigma\left(=A_{S} / A_{N}\right)$ drops by up to $5 \%$. This suggests that even small impacts of climate change can lead to significant changes in the number of migrants.

Table 1: Effect of climate change on migration

\begin{tabular}{c|c|r|r|r|r|r}
\hline \hline decrease in $\sigma$ & \multicolumn{1}{|c|}{0} & \multicolumn{1}{c|}{$-1 \%$} & \multicolumn{1}{c|}{$-2 \%$} & \multicolumn{1}{c|}{$-3 \%$} & \multicolumn{1}{c}{$-4 \%$} & \multicolumn{1}{c}{$-5 \%$} \\
\hline Migrants in 2050, (in millions) & 98.77 & 150.95 & 205.80 & 263.45 & 324.02 & \multicolumn{1}{l}{387.64} \\
change in migrants' stock & $0.00 \%$ & $52.84 \%$ & $108.38 \%$ & $166.74 \%$ & $228.07 \%$ & $292.49 \%$ \\
share of migrants (North) & $8.98 \%$ & $13.72 \%$ & $18.71 \%$ & $23.95 \%$ & $29.46 \%$ & $35.24 \%$ \\
share of migrants (Sorth) & $1.23 \%$ & $1.89 \%$ & $2.57 \%$ & $3.29 \%$ & $4.05 \%$ & $4.85 \%$ \\
share of migrants (World) & $1.50 \%$ & $2.29 \%$ & $3.12 \%$ & $3.99 \%$ & $4.91 \%$ & $5.87 \%$ \\
\hline \hline
\end{tabular}

Source: GTAP, UN Population Division and own computations

The results in this section immediately raise questions of various concerns: Empirically, how can we differ between incentives for migration, namely purely utilitarian incentives and forced migration? Ethically, what value do we give to space and place (or origin) and is someone responsible for taking the migrants? Politically, how are we to deal with possible migration of up to $35 \%$ of Northern country's population? Economically, what is the effect of various policies on the number of migrants, on the inequality between North and South, as well as on the amount of climate change?

Though each of the above questions poses challenging problems, we are only going to deal with the economic ones here. In the subsequent section 5 we deal with policies of the North. 


\section{$5 \quad$ Northern Policies}

We shall now investigate the effects of several possible policies undertaken by the North. The first policy is an immigration policy whereas the second one leads to greener production. In the last part of this section we assume policies are costly and calibrate whether the US or Europe would, in the long-run, invest more in green technology or immigration policy. In the subsequent propositions, whenever we refer to 'abstracting from climate change', we mean $A_{S}\left(T_{t}\right)=A_{S} \equiv$ const, $\forall T$.

We assume that policies may certainly bear costs at the time they are implemented, but these costs will be zero in the long-run. We believe this assumption holds true for example for R\&D expenditure in emission reductions: If a greener technology is developed once, then it is clear that further R\&D expenditure is not necessary. Similarly, immigration policy which leads to a higher probability of obtaining a job for the migrants only requires a discussion in the parliament. Thus, long-run costs can be assumed zero. We shall analyze the impact of either policy now.

\section{$5.1 \quad$ Immigration policy}

We here interpret changes in immigration policy of the North as changes in migration costs. A less restrictive immigration policy would then lead to lower migration costs (increases in $x$ ). It is certainly true that many northern governments undertake immigration policies in order to regulate the amount of migrants. Here one can imagine that the North takes responsibility for the climate change which it imposes upon the South and therefore relaxes its immigration policy. Our objective is to see the long-run effect of changes in immigration policy on the amount of migrants, the environment as well as on North-South inequality.

Proposition 3 Abstracting from climate change, if immigration policy is relaxed, i.e. the subjective migration costs decrease, then more people will migrate which unambiguously increases the utility in the south and lowers that of the north. Including climate change, this further increases the long-run number of migrants; may lead to a completely deserted South; aggravate climate change; decrease or increase North-South inequality. 
The proof goes as follows. We can calculate the change in indirect utility from a change in the immigration policy to be

$$
\begin{gathered}
\frac{d \tilde{u}_{i}^{a m}}{d x}=\frac{1+\rho}{1-\alpha}(\alpha+\beta-1) \frac{\partial L_{i}}{\partial M^{a m}} \frac{d M^{a m}}{d x} . \\
\frac{d M^{a m}}{d x}=\frac{1-\alpha}{1-\alpha-\beta} \frac{1}{x}\left(A_{N} x^{1-\alpha}\right)^{\frac{1}{\alpha+\beta-1}}\left[\frac{A_{S}^{\frac{1}{\alpha+\beta-1}}\left(\bar{L}_{N}+\bar{L}_{S}\right)}{\left(A_{S}^{\frac{1}{\alpha+\beta-1}}+\left(x^{1-\alpha} A_{N}\right)^{\frac{1}{\alpha+\beta-1}}\right)^{2}}\right]>0
\end{gathered}
$$

Conclusively, $\frac{d \tilde{u}_{S}^{a m}}{d x}>0$ for the south and $\frac{d \tilde{u}_{N}^{a m}}{d x}<0$ for the North. Intuitively, the increased population pressure in the north will reduce steady state utility in the North, whereas the higher per capita income will increase indirect utility in the South. This, of course, is a direct implication of the DRTS.

However, things change slightly when we take climate change into account, too. We obtain the result that the impact of changes in migration costs on indirect utility then crucially hinges on how strong the feedback of migration itself is on climate change. Mathematically we get

$$
\frac{d \tilde{u}_{S}^{a c m}}{d x}=\frac{1+\rho}{1-\alpha}\left[\frac{1-\alpha-\beta}{L_{S}}+\frac{1}{A_{S}} A_{S}^{\prime}\left(K_{N}\right) \frac{\partial K_{N}}{\partial L_{N}}\right] \frac{\partial M^{a c m}}{\partial x},
$$

with $A_{S}^{\prime}\left(K_{N}\right) \frac{\partial K_{N}}{\partial L_{N}}<0$ and

$$
\frac{d \tilde{u}_{N}^{a c m}}{d x}=-\frac{1+\rho}{1-\alpha} \frac{1-\alpha-\beta}{L_{N}} \frac{\partial M^{a c m}}{\partial x},
$$

where

$$
\frac{d M^{a c m}}{d x}=\frac{\frac{\partial M^{a m}}{\partial x}}{1-\frac{\partial M^{a c m}}{\partial A_{S}} \frac{\partial A_{S}}{\partial K_{N}} \frac{\partial K_{N}}{\partial L_{N}}} .
$$

The nominator is positive and the denominator is positive if $\frac{\partial M^{a c m}}{\partial A_{S}}>0$. However, calculating this derivative we get

$$
\frac{\partial M^{a c m}}{\partial A_{S}}=-\frac{1}{1-\alpha-\beta} A_{S}^{\frac{2-\alpha-\beta}{\alpha+\beta-1}}\left(x^{1-\alpha} A_{N}\right)^{\frac{1}{\alpha+\beta-1}} \frac{\bar{L}_{S}+\bar{L}_{N}}{\left(A_{S}^{\frac{1}{\alpha+\beta-1}}+\left(x^{1-\alpha} A_{N}\right)^{\frac{1}{\alpha+\beta-1}}\right)^{2}}<0 .
$$

A necessary condition for an interior solution to $M^{a c m}$ requires $\frac{\partial M^{a c m}}{\partial A_{S}} \frac{\partial A_{S}}{\partial K_{N}} \frac{\partial K_{N}}{\partial L_{N}}<1$. This condition holds only if changes in $A_{S}$ have small impacts on the number of migrants or if climate change has minimal impacts on TFP in the South. Put differently, if the migration costs change, then the impacts unfold subsequently as follows. Initially, more 
people wish to migrate since the costs are lower, and thus the perceived benefit of moving to the north is higher. The secondary effect of this is, however, that more migrants pollute more and therefore induce a further decrease in the productivity of the South. If migrants have only a small impact on climate change, then $M^{a c m}$ will be insignificantly higher than $M^{a m}$. However, if the impact of migrants on total climate change is large enough and climate change impacts the migration decisions strongly, then this could potentially lead to a corner solution: All inhabitants from the South wish to migrate to the North. In any case we can conclude that $d M^{a c m} /(d x)>d M^{a m} /(d x)$.

The effect on the environment is similar. Since temperature in steady state is $T=$ $g\left(\frac{\gamma \mu}{\delta} K_{N}\right)$, we can then deduce that climate change is somewhat proportional to changes in $K_{N} . K_{N}$ in steady state is given by $K_{N}=\left[\frac{\rho}{1+\rho} \beta A_{N} L_{N}^{\beta}\right]^{\frac{1}{1-\alpha}}$, implying that $\frac{d K_{N}}{d x}$ depends on $\frac{d M^{a c m}}{d x}$. Since we know that $M^{a c m}>M^{a m}$, it is clear that climate change will thus be intensified.

The effect on inequality is as follows. We define North-South inequality simply as the ratio $\tilde{u}_{N} / \tilde{u}_{S}$. Inequality is minimized when $\tilde{u}_{N}=\tilde{u}_{S}$ and increases ${ }^{11}$ when the ratio deviates from 1 . Since we know that steady state per capita utility of the North in the benchmark case is higher than the one of the South, then a reduction in inequality from the immigration policy requires $d\left(\tilde{u}_{N} / \tilde{u}_{S}\right) /(d x)<0$. This is equivalent to the condition

$$
\frac{1+\rho}{1-\alpha}\left[-(1-\alpha-\beta)\left(\frac{\tilde{u}_{S}}{L_{N}}+\frac{\tilde{u}_{N}}{L_{S}}\right)-\tilde{u}_{N} \frac{A_{S}^{\prime}\left(K_{N}\right)}{A_{S}} \frac{\partial K_{N}}{\partial L_{N}}\right] \frac{d M^{a c m}}{d x}<0 .
$$

The first term inside the brackets is negative and relates to the DRTS. It vanishes if there are no DRTS, since then indirect utility is not (directly) affected by migration. Since $\tilde{u}_{S} \uparrow$ if $M^{a c m} \uparrow$, then due to DRTS fewer people can share more wealth. The indirect effect is given by the second term, which is positive. It relates to the effect of migrants on climate change. The more migrants move to the North, the more they will add to world pollution and the stronger will be the climate change effects in the South. This feedback will work against equality. We can therefore conclude that world inequality will increase or diminish depending on which of the terms is stronger.

\subsection{Green Technology}

Many researchers believe that technological improvements are the key means of relieving production from the climate change constraints, especially given that preferences are not

\footnotetext{
${ }^{11}$ For simplicity we assume that $\tilde{u}_{i}>0$.
} 
expected to change sufficiently. Furthermore, these investments need to happen now, in order to prevent climate damages in the distant future. Researchers sometimes find that, due to discounting or uncertainties, it does not pay to take these investments now. Our approach here relies on abstracting from those short-run problems and on only looking at the potential effect of an investment in green technology today on the long-run number of migrants, climate change and North-South inequality in the future.

We therefore assume that at one point in time the North can invest in green technology which reduces the amount of emissions per unit of production. The investment costs will obviously have no impact on the production potential in the long-run since they will be sunk. As we defined climate change as $T=g\left(\frac{\gamma \mu}{\delta} K_{N}\right)$, with $A_{S}(T)$ denoting the impact thereof, then within the terms of our model, this means we analyze changes in $\mu$. Obviously, decreases in $\mu$ signify a greener technology. We collect the results in the subsequent proposition.

Proposition 4 Adopting a greener technology will reduce the long-run number of migrants; reduce climate change directly and indirectly; either increase or decrease NorthSouth inequality.

To prove the results presented in this proposition, we follow the approach from before and derive

$$
\begin{aligned}
\frac{d \tilde{u}_{S}^{a c m}}{d \mu} & =\frac{1+\rho}{1-\alpha} \frac{1}{A_{S}} \frac{\partial A_{S}}{\partial \mu}+\frac{1+\rho}{1-\alpha}\left[\frac{1}{A_{S}} \frac{\partial A_{S}}{\partial M^{a c m}}+(1-\alpha-\beta) \frac{1}{L_{S}}\right] \frac{d M^{a c m}}{d \mu} \\
\frac{d \tilde{u}_{N}^{a c m}}{d \mu} & =-(1-\alpha-\beta) \frac{1+\rho}{1-\alpha} \frac{1}{L_{N}} \frac{d M^{a c m}}{d \mu}
\end{aligned}
$$

where

$$
\frac{d M^{a c m}}{d \mu}=\frac{\frac{\partial M^{a m}}{\partial \mu}}{1-\frac{\partial M^{a c m}}{\partial A_{S}} \frac{\partial A_{S}}{\partial K_{N}} \frac{\partial K_{N}}{\partial L_{N}}}
$$

We can calculate

$$
\frac{\partial M^{a m}}{\partial \mu}=-\frac{A_{S}^{\frac{2-\alpha-\beta}{\alpha+\beta-1}}}{1-\alpha-\beta}\left[\frac{\left(x^{1-\alpha} A_{N}\right)^{\frac{1}{\alpha+\beta-1}}\left(\bar{L}_{N}+\bar{L}_{S}\right)}{\left(\left(A_{S}\right)^{\frac{1}{\alpha+\beta-1}}+\left(x^{1-\alpha} A_{N}\right)^{\frac{1}{\alpha+\beta-1}}\right)^{2}}\right] \frac{\partial A_{S}}{\partial \mu}>0
$$

An interior solution for $M^{a c m}$ either requires a small enough impact of changes in productivity on the total amount of migrants or a small impact of climate change on productivity in the South. We then know that $d M^{a c m} /(d \mu)>d M^{a m} /(d \mu)$. 
In order to sign the effect of $\mu$ on $\tilde{u}_{S}^{a c m}$ we need to manipulate the ambiguous term in the square brackets of $\frac{d \tilde{u}_{S}^{a c m}}{d \mu}$. Some manipulations together with the results of the last paragraph give us

$$
\frac{d \tilde{u}_{S}^{a m}}{d \mu}=\frac{1+\rho}{1-\alpha}\left[\frac{1}{A_{S}}-\frac{1}{L_{S}} A_{S}^{\frac{2-\alpha-\beta}{\alpha+\beta-1}}\left(\frac{\left(x^{1-\alpha} A_{N}\right)^{\frac{1}{\alpha+\beta-1}}\left(\bar{L}_{N}+\bar{L}_{S}\right)}{\left(\left(A_{S}\right)^{\frac{1}{\alpha+\beta-1}}+\left(x^{1-\alpha} A_{N}\right)^{\frac{1}{\alpha+\beta-1}}\right)^{2}}\right)\right] \frac{\partial A_{S}}{\partial \mu} .
$$

As $\frac{\partial A_{S}}{\partial \mu}<0$, then $\frac{d \tilde{u}_{S}^{a m}}{d \mu}<0$ if the term inside the square brackets is positive. Simple manipulation shows that this holds if $A_{S}^{\frac{1}{\alpha+\beta-1}}+\left(x^{1-\alpha} A_{N}\right)^{\frac{1}{\alpha+\beta-1}}>0$, which is always true. We can therefore unambiguously conclude that $\frac{d \tilde{u}_{S}^{a c m}}{d \mu}<0$ and $\frac{d \tilde{u}_{N}^{a c m}}{d \mu}<0$. Therefore, investment in green technology is a win-win strategy in the long-run.

Since $d M^{a c m} /(d \mu)>0$, it is straight-forward to show that in the long-run the environment is in a better state, as total production in the North is lower due to fewer migrants. In addition, adopting a greener technology also bears a direct effect on the environment since the emissions per unit of capital are reduced. This could be called a double-dividend policy in favor of the environment.

Our analysis of North-South inequality suggests the following. Our measure of inequality is reduced if

$$
-\tilde{u}_{N} \frac{d \tilde{u}_{S}^{a c m}}{d \mu}-\frac{1+\rho}{1-\alpha}\left[(1-\alpha-\beta) \frac{\tilde{u}_{S}}{L_{N}}+\tilde{u}_{N} \frac{A_{S}^{\prime}\left(K_{N}\right)}{A_{S}} \frac{\partial K_{N}}{\partial L_{N}}\right] \frac{d M^{a c m}}{d \mu}<0 .
$$

An investment in greener technology (implying $\mu \downarrow$ ) today leads to a reduction in the number of migrants in the long-run. Fewer migrants increase per capita welfare in the North, which raises inequality (second term). However, fewer migrants in the North implies also less climate change, which raises productivity in the South and thus reduces inequality (third term). In addition, climate change is directly reduced through the use of greener technology, which again reduces inequality (inside first term). Then, if the DRTS in the South are not too large (inside first term), this will imply an overall decrease in world inequality.

\subsection{Investment in clean technologies or in border controls}

Should the government invest in greener technology or in immigration controls? Assume the government has a fixed amount of resources $\tau=\bar{\tau}$, then the budget constraint can be written as $\tau_{\mu}=\bar{\tau}-\tau_{x}$. The northern government will choose the optimal share of 
tax revenues to allow to border controls by maximizing the utility of a northern citizen subject to $\tau_{x}$.

$$
\frac{d \tilde{u}_{N}}{d \tau_{x}}=\frac{\partial u_{N}}{\partial M} \frac{\partial M}{\partial \tau_{x}}
$$

The sign of $\frac{d \tilde{u}_{N}}{d \tau_{x}}$ will determine if the government will spend more on border controls or more on green technologies. Since $\frac{\partial u_{N}}{\partial M}<0$ the government decisions will depend on the sign of $\frac{\partial M}{\partial \tau_{x}}$. Thus for a given tax rate $\bar{\tau}$, if $\frac{d M}{d \tau_{x}}<0$, then the government will invest more in border controls while reducing its investments in green technologies. The reverse is true if $\frac{d M}{d \tau_{x}}>0$.

Since the theoretical conditions do not provide interpretable results we shall give a numerical illustration. Consider the North to be either EU-15 (EU) or North-America (NAM), which comprises United States and Canada. Will each of these two regions spend more on green technologies or on border controls? In order to address this issue we do a similar extrapolation exercise as before and choose the following functional forms: $A_{S}\left(K_{N}\right)=\frac{A_{S}}{1+\omega T}$, $T=\mu K_{N}, x=\frac{\bar{x}}{1+a \tau_{x} Y_{N}}, \mu=\frac{\bar{\mu}}{1+b \tau_{\mu} Y_{N}}$.

In 2050, populations in Europe and North-America there will be respectively $L_{E U}=0.328$ and $L_{N A M}=0.328$ bn of people, while in the south $L_{S}=8.165$. The share of migrants from developing countries in $E U$ and $N A M$ corresponds to $10.13 \%$ and $4.9 \%$ in 2000 . We keep these shares to constant in 2050. We take the following values $\alpha=0.37, \beta=0.44$, $\rho=0.9, \tau_{N}=0.1$ and GDP PPP equals to $Y_{N A M}=14.76$ and $Y_{E U}=14.95$ thousands bn in 2000. We assume that per capita GDP increases by $1 \%$ in each of these two regions and multiply by the respective populations to obtain the GDP in 2050. Following the procedures from above, we obtain $K_{N A M}=12.25$ and $K_{E U}=7.50, A_{N}=21.14$ in 2050. TFP in the south is calculated as above, giving $A_{S}=4.429$. We set the unknown parameters (subject to subsequent sensitivity analysis) $\omega=0.05, b=1$ and $a=0.0065$. We know that $\mu=\frac{E}{K_{N}}$ and that emissions amount to $E_{N A M}=6.05, E_{E U}=3.12$ thousand bn tons in 2000 in respectively North-America and in EU-15. We obtain $\mu_{N A M}=1.13$ and $\mu_{N A M}=0.57$ for 2000 and keep these values constant for 2050. Immigration costs are calibrated as before: we obtain $x_{N A M}=0.063$ and $x_{E U}=0.077$. The parameters $\bar{x}$, $\bar{\mu}, \bar{A}_{S}$ are then calibrated to match $x, \mu$ and $A_{S}$.

We obtain, given the respective structures of both economies, that North-America will invest more in immigration costs $\left(\tau_{x}=84.66 \%\right)$ while Europe spends most of its tax revenues on green technologies $\left(\tau_{\mu}=85.19 \%\right)$. Interestingly, we can already observe this behavior currently. However, it must be said that this result rests solely on a per capita utilitarian approach, neglecting any other ethical or political dimensions. 


\section{Conclusion}

In this article we investigate the relationship between climate change and international migration. We make use of a two-regions overlapping generations model similar to Galor [19] but allow for climate change to affect the productivity in the South.

Our main findings are that climate change will most likely increase world migration and that even small changes in its impact can imply significant changes in the amount of migrants in the long-run. A simple calibration exercise suggests the the number of migrants increase by a factor of four if climate change reduces southern productivity by approximately 5 percent. However, from our empirical overview in the first part of this paper it is very likely that the reduction in southern productivity exceeds 5 percent in the future. Thus, it goes without saying that migration is expected to re-shape world orders if it is not properly guided by international policies.

We then investigate the impact which a world migration institute might have on the stock of global migrants. In this setting we allow the institute to internalize the snowball effects which the migrants themselves have on the global climate and we allow the institute to take the total costs of migration into account. We look at two social welfare functions, a utilitarian one and an egalitarian one, the solution of both then being compared to the one obtained in the laissez-faire economy. We notice that, given our benchmark calibration, the utilitarian institute is likely to choose more world migration even if its preference toward the North is relatively low. Similarly, the egalitarian institute will choose a larger stock of world migrants which we believe is due to the relatively low migration costs.

We also analyze what effect a softer immigration policy and investment in greener technology might have on the long-run number of migrants, on the environment and North-South inequality. Both policies could be undertaken for different reasons. Whereas we interpret the softer immigration policy as an aftercare policy which makes the North take its responsibility for the effects of climate change which it itself imposed upon the South, the investment in greener technology can easily be understood as a precautionary or forethought policy. We show that the immigration policy clearly increases the number of migrants but worsens climate change and has an ambiguous effect on North-South inequality. On the contrary, the investment in greener technology leads to fewer long-run migrants, a better environment, but again an ambiguous sign for the inequality measure. It is therefore clear that any policy undertaken by the North will depend on the importance which the North places upon displacement of people, climate change or inequality. Importantly, the qualitative results do not depend on whether the costs of the policies are sunk in the future or whether the policies incur continuous costs. With a numerical 
example we show that the US would prefer to invest in immigration policy, whereas the EU would prefer to invest in green technology, a result which stems from the differences in production technologies.

There are many extensions which this model could see. Firstly, it should be interesting to analyze the short-run migration decisions and compare these to the long-run choices. Since we know that a policy which has positive effects in the long-run might have significant costs in the short-run, it can be important to compare the costs and benefits of both. Furthermore, though in the long-run this is clearly unimportant, in the short-run we could see significant impacts of population growth. Including this in this model will pose challenging problems. 


\section{References}

[1] A. A. Afolayan and I. O. Adelekan. The role of climatic variations on migration and human health in africa. The Environmentalist, 18(4):213-318, 1999.

[2] International Energy Agency. International energy annual 2004. 2004.

[3] M.E. Assessment. Ecosystems and Human Well-being: Synthesis. Island Press, 2005.

[4] The World Bank. 2006 world development indicators online. Technical report, Development Data Group, 2007.

[5] S. Basu and J. G. Fernald. Returns to scale in u.s. production: Estimates and implications. Journal of Political Economy, 105(2):249-83, April 1997.

[6] V.R. Bencivenga and B.D. Smith. Unemployment, Migration, and Growth. Journal of Political Economy, 105(3):582, 1997.

[7] R. Black. Environmental Refugees: Myth Or Reality? UNHCR, 2001.

[8] B. Brown. Onions. Southern Idaho fertilizer guide, 2000. University of Idaho.

[9] BD Brown, AJ Hornbacher, and DV Naylor. Sulfur-coated Urea as a Slow Release Nitrogen Source for Onions. Cooperative Extension Service, University of Idaho, College of Agriculture, 1988.

[10] Les Christie. Growth states: Arizona overtakes nevada: Texas adds most people overall; louisiana population declines nearly 5\%. Technical report, CNN, December $22,2006,2006$.

[11] A. Cigno. Growth with Exhaustible Resources and Endogenous Population. Review of Economic Studies, 48(2):281-287, 1981.

[12] B. Crettez, P. Michel, and J.P. Vidal. Time preference and labour migration in an OLG model with land and capital. Journal of Population Economics, 9(4):387-403, 1996.

[13] D. de La Croix and P. Michel. A Theory of Economic Growth: Dynamics and Policy in Overlapping Generations. Cambridge University Press, 2002.

[14] F. Docquier and A. Marfouk. International Migration, Remittances and Development. 2006. 
[15] M. Ezra. Ecological Degradation, Rural Poverty, and Migration in Ethiopia: A Contextual Analysis. Population Council, 2001.

[16] G. Facchini and G. Willmann. The political economy of international factor mobility. Journal of International Economics, 67(1):201-219, September 2005.

[17] C. Flavin and O. Tunali. Ein klima der hoffnung. Worldwatch Paper, 1998.

[18] FOOD and AGRICULTURE ORGANIZATION. The State of Food and Agriculture 2003-2004. FAO Agriculture Series (SOFA), 2004.

[19] Oded Galor. Time preference and international labor migration. Journal of Economic Theory, 38(1):1-20, February 1986.

[20] S. Ghatak, P. Levine, and S.W. Price. Migration Theories and Evidence: An Assessment. Journal of Economic Surveys, 10(2):159-198, 1996.

[21] F Hahn and R Solow. A critical essay on modern macroeconomic theory. Blackwell, Oxford, 1995.

[22] J.R. Harris and M.P. Todaro. Migration, Unemployment and Development: A TwoSector Analysis. The American Economic Review, 60(1):126-142, 1970.

[23] S. Henry, B. Schoumaker, and C. Beauchemin. The Impact of Rainfall on the First Out-Migration: A Multi-level Event-History Analysis in Burkina Faso. Population \& Environment, 25(5):423-460, 2004.

[24] G. Hugo. Environmental Concerns and International Migration. International Migration Review, 30(1):105-131, 1996.

[25] INCCCD. The almeria statement on desertification and migration. Technical report, Intergovernmental Negotiating Committee for a Convention to Combat Desertification, 1994.

[26] IPCC. Climate Change 2007 - Impacts, Adaptation and Vulnerability. Cambridge University Press, 2007.

[27] TAR IPCC. Intergovernmental Panel on Climate Change: Climate Change 2001Third Assessment Report. 2001.

[28] Borjas G. J. The labor demand curve is downward sloping: Re-examining the impact of immigration on the labor market. The Quarterly Journal of Economics, 118(4):1335-1374, November 2003. 
[29] L. Kaye. The reckoning. Far Eastern Economic Review, 27:24-30, 1994.

[30] Robert McLeman. Migration out of 1930s rural eastern oklahoma: Insights for climate change research. Great Plains Quarterly, 26(1):27-40, 2006.

[31] Chonggang Xu Min Chen and Rusong Wang. Key natural impacting factors of china's human population distribution. Population Environment, 28:187Ü200, 2007.

[32] Neidecker-Gonzales O. Carletto C. Munguia M. Medina J.M. Morris, S.S. and Q. Wodon. Hurricane Mitch and the Livelihoods of the Rural Poor in Honduras. World Development, 30(1):49-60, 2002.

[33] N. Myers. Environmentally-induced displacements: the state of the art. Technical report, Environmentally-Induced Population Displacements and Environmental Impacts Resulting from Mass Migration, International Symposium, 1996.

[34] International Federation of Surveyors. The Contribution of the Surveying Profession to Disaster Risk Management. Technical Report 38.

[35] World Health Organization. The World Health Report 1996: Fighting Disease, Fostering Development. World Health Organization, 1996.

[36] R. Nicholls P. Levy R. Warren, N. Arnell and J. Price. Understanding the regional impacts of climate change. Technical report, Tyndall Centre for Climate Change Research Working Paper 90, 2006.

[37] A. Razin and E. Sadka. Migration and pension with international capital mobility. Journal of Public Economics, 74(1):141-150, 1999.

[38] C. Rosenzweig and D. Hillel. The dust bowl of the 1930s: Analog of greenhouse effect in the great plains? Journal of Environmental Quality, 22(1):9-22, 1993.

[39] N. Stern. The Economics of Climate Change, The Stern Review. Cambridge University Press, 2007.

[40] M.M. Berk M. Janssen E. Kreileman Swart, R. and R. Leemans. The safe landing analysis: risks and trade-offs in climate change, pages 193-218. Pergamon and Elsevier Science, London, United Kingdom, 1998.

[41] J.P. Vidal. The effect of emigration on human capital formation. Journal of Population Economics, 11(4):589-600, 1998. 